\title{
Computer-Assisted Testing in Intermediate Language Courses
}

An experimental second-year language class and a control class read eight short stories in the target language and studied six grammatical topics during a 15-week academic term. The experimental class took eight computerized quizzes and tests, consisting of true/false, multiple-choice, and cloze questions. Students in the control class did not use computers for testing.

The experimental group did significantly better than the control group on the final examination. Students in the experimental group also said they "liked" the computerized quizzes and tests.

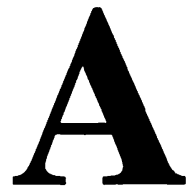

$s$ teachers of intermediate language courses, we make pedagogical choices that directly affect the courses we teach and the students in them. Some of the choices we make revolve around the following issues: how do we teach our students to read in the target language; how many texts (stories) can we expect them to have read by the end of term; should we stress vocabulary over syntax or vice versa; should our students be able to give word-for-word translations of assigned reading texts; ' and, what about the testing of reading comprehension. Whatever else may be said about these linguistic issues, teachers use experience-their own and that of others-to help them decide what to teach and how their students can best learn in order to improve reading comprehension skills.

Experience notwithstanding, improving target language reading comprehension skills does not come easily for many students. As concerned teachers, we cannot help but wonder if better ways exist to help our students achieve proficiency in understanding a foreign language. Like many of our colleagues at every level of education, we wonder if the computer can be exploited to help students achieve higher levels of competence more easily and quickly.

To determine whether the computer can be usefully exploited by intermediate language students to help them improve their reading proficiency, the author-who teaches intermediate German courses-investigated the topic of reading comprehension in German by a detailed examination of major research findings. Then-based on what is known about reading comprehensionhe devised his own experimental study in order to discover if the computer can significantly improve student performance in intermediate foreign language courses.

Reading Experiments in the Comprehension of German

Although the professional literature could easily convince many people that computers are, indeed, everywhere, they were not being used in every intermediate foreign language course in the summer of 1987-if research on the subject of computers and reading in foreign languages is any indication. At that time, the author requested a search by Bibliographic Retrieval Services to uncover all the research conducted in the area of computers and reading in foreign languages. The search yielded only ten articles. Of these ten, three dealt with experiments in German; these threetogether with related research-became the focus of the author's in-depth examination of relevant research.

The Research of Bruce Beatie. Bruce Beatie declared that we often forget those students who only want a reading knowledge of a foreign language. Often in the sciences, these students want to be able to read the current research in their fields of study. While it is true that the reading skill is often the fastest to develop-a skill that students retain even after leaving the classroom-courses designed to teach target language reading proficiency are usually not in great enough demand 
at smaller colleges and universities to justify their being offered on a regular basis.

This being the case, Beatie developed a selftutorial method for learning to read German at Cleveland State University. This tutorial method involves using the traditional "decoding" practice someone might use to read Latin or Old High German. Because this traditional process would be considered too slow for today's students, Beatie incorporated the following elements to enhance the self-study program: First, he added a recording of the written text, encouraging the student to read and listen to the entire text first without stopping to translate each word; secondly, he gave students self-checking quizzes requiring an $80 \%$ level of mastery on a given assignment before students could continue to the next level; and, thirdly, the students were given regular practice in both sentence analysis, using "diagramming" and question-making. In turn, these strategies were broken down into a ten-step method which the student was required to follow strictly.

The reading text used by Beatie was Harold von Hofe's Faust, Leben, Legende und Literatur. In addition to the text, students purchased an 84-page syllabus, a German-English dictionary, and a short reference grammar. These materials were supplemented by 300 pages of self-testing quizzes and mid-term and final examinations totaling 136 pages.

For students who did not have the knowledge of English grammar needed to identify subjects, verbs, and direct objects, a "pre-course" in English was available. In addition, a short study of cognates and an introduction to German grammar was also added to the "pre-course."

Originally designed to teach students reading skills, this program could also be used by students who were unable to enroll in a regular German course to develop or maintain their reading skills (Beatie, 1979).

The Research of David Weible. In his research conducted at the University of Chicago, Weible describes the development of a computer program designed to teach high frequency vocabulary, basic syntax, and reading skills by inferring the meaning. Reading in this program is a problem-solving exercise; the student is forced to apply his or her accumulated knowledge and experience.

Weible designed his interactive computerbased program in order to meet the needs of beginning students with low linguistic aptitude and varying degrees of motivation. In this program, students were shown a short passage written partially in English and partially in German. The students were then asked to type in the correct English meaning of the German words and phrases. After the students typed their response, the computer program indicated if the response was correct. If the response was incorrect, the program would display the correct answer.

The execution of immediate response had to be modified, because some students simply typed in anything, got the correct response, copied it down, proceeded through the program-in order to achieve the required $92 \%$ accuracy rate-and thereby gained access to the next passage. Modification of the program took the form of a minimum correct response at $33 \%$ before the program provided students with answers to the question.

Weible chose textual passages which would have intrinsic appeal to young people. He selected 16 passages for the ten-week term. The first four passages were from Alice in Wonderland, followed by two from the Lord of the Rings, two from H.P. Lovecraft's "The Rats in the Walls," four from a highly abridged account of Sherlock Holmes' final case, and four passages based on the Grimm fairy tale, Repunzel.

In the sequence of passages, the relative percentage of Germany vocabulary increases from $30 \%$ in the first passage to $88 \%$ in the last one. Obviously, the abundant use of English at the beginning helps students guess the contextual meaning of the German words. Furthermore, the beginning passages introduce and drill German definite and indefinite articles, prepositions, conjunctions, numerals, pronouns, and possessive adjectives. Nouns and adjectives are included in the later passages. To insure that he was using vocabulary with high frequency occurrence in written German, Weible used word frequency lists. As a result, a relatively high percentage $(21 \%)$ of the vocabulary in the computer program was common to the vocabu- 


\section{Journal of Educational Techniques and Technologies}

laries of all 12 stories.

This program does more than simply tell students if responses are correct; it provides more specific information such as telling them that a verb tense, for example, is incorrect. Additionally, the program also indicates if the meaning for a given word-learned in an earlier drilldiffers in a later passage. As a safeguard, the program requires students to proceed through the material sequentially-necessary, in part, because the syntax of the English passages is gradually altered to conform to German patterns.

The number of times a student worked on a particular passage was recorded. In addition, each student completed an attitudinal questionnaire after the fourth, eighth, and twelfth passages. Comments from these questionnaires were instrumental in initiating improvements in the program.

First pilot-tested by a group of beginning German students, the program received the following treatment: Students worked with it once a week without any specific reinforcement in class; their work with the computer program did not affect the course grade. As a post-test, students were asked to sight read a passage. Although the variation in the average scores of students using the computer program and those who did not were not statistically significant, the results were encouraging.

After the initial pilot, follow-up sight translations-with certain words and phrases singled out for translation-were administered in class. Of these translations, three accounted for $10 \%$ of the student's final grade. To measure how much students had learned, a sight translation of an unfamiliar passage from German to English was administered. A group using the computerbased program demonstrated significant superiority in vocabulary, structure, and total score over a group which did not use it (Weible, 1980).

The Research of Dale L. Lange. Dale Lange and his associates, Richard Raschio and Paul Wieser from the University of Minnesota, describe an ambitious research project. It is the aim of their research to go beyond simple text processing; instead, they wanted to promote "higher order cognitive processing skills." Their model consists of three phases: intake, personalization, and extension.

During the "intake phase," the learner reads the text. A "preview section" introduces structures, vocabulary, and information which the learner will encounter in the text. As such, this section helps orient the learner. "Help screens," which provide decoding assistance, are also available. The information in the help screens are not glosses or word-for-word translations, but rather they consist of target language sentences that demonstrate the meaning of a key word.

Comprehension of the text is checked in a variety of ways. The learner identifies the correct sequence of sentences, chooses the correct summary, answers multiple-choice and true/false questions, and responds in writing to a picture or text segment. Once the learner's comprehension level is at a satisfactory level, he or she may proceed to the "personalization phase."

During the "personalization phase," the learner must answer questions and arrange the responses in paragraph form to produce a coherent story or description which uses the processed information from the texts in a more original and personalized context.

In the "extension phase," the learner goes beyond the computer-assisted instruction format of the lesson. He or she may be required to read additional materials and make comparisons and contrasts based on information already learned in the lesson up to this point.

This model includes a "management system," which monitors the progress of the student and records information useful in determining the status of the lesson. In addition, this program allows learners to continue from where they "left off" during a previous session. Because there are different levels of difficulty in the comprehension exercises, the management system chooses a level appropriate to the needs of individual students.

This project at the University of Minnesota was funded, in part, by IBM; it is also part of a cooperative undertaking among two colleges and four departments at the university. It is the author's judgment that this model will be one for other institutions to emulate (Lange, 1985).

The Research of Marva Barnett. Marva Barnett is among those researchers who see 
reading as an "interactive process rather than a "passive" skill. She readily admits that it is difficult to determine exactly what the reading process entails, however. The general consensus seems to be that several factors are at play: perception of print, reader's background knowledge and interest in the text, individual facility with various reading strategies (including inferencing, predicting, using illustrations), and language knowledge (including grammar control and vocabulary range).

Aware that a number of leading educators emphasize vocabulary over grammar, Barnett decided to test the following hypothesis in her study: The ability of English-speaking readers to comprehend a French text depends more on lexical/semantic analysis than on syntactic analysis.

One hundred thirty-one fourth-semester French students participated in the Barnett study. The students were given a multiple-choice cloze test for each of two stories; correct choices for half of the blank spaces depended upon a knowledge of syntax; the other half depended on a knowledge of vocabulary or upon attention to semantics within the text. Students also summarized a text in English.

Barnett found that vocabulary and syntactic skills are necessary to English speakers' reading comprehension of French. Furthermore, she also found that these skills interact with each other. She suggests, based on her research, that pedagogical applications should grow from research-supported theory, and that studies are needed to address the questions of what are the most effective ways to teach vocabulary and syntax in order to train efficient readers (Barnett, 1984).

\section{Improving Intermediate Language Courses at Western Michigan}

Keeping Marva Barnett's suggestionconcerning the need to find the most effective ways to train efficient readers-in mind, the author set out to improve his method of instruction in intermediate German courses at Western Michigan University.

A fourth semester German course is critical: For many students, it is their last German course; for others, it is a springboard for an undergrad- uate minor or major in German. As teacher of intermediate German courses, the author felt that students needed to master more vocabulary, know the grammar reasonably well, and understand what they had read.

Such being the case, the author-with the help of two assistants-developed an experimental design to test the following hypothesis: Computerized quizzes and tests can aid intermediate college students in learning vocabulary, mastering grammar, and comprehending texts more effectively than conventional approaches to teaching intermediate German.

\section{Preliminaries}

First Day of Class. On the first day of fall semester, students were informed of the course goals. In addition, they were told that $40 \%$ of class time would be spent on grammar, $40 \%$ on reading comprehension, and $20 \%$ on developing listening skills.

Two Days Later. Several days later, students took a pre-test to ascertain their reading comprehension, knowledge of correct grammatical patterns, and listening skills. The entire test consisted of multiple-choice and true/false statements. The same test was given as a posttest at the end of the semester as part of the final exam. By giving the same test at the end of the term, the author hoped to measure how much each student had improved.

\section{The Control Group/The Conventional Treatment}

The author's conventional method of teaching intermediate German to the control group was as follows: At the beginning of each story, students were given a set of three pictures, depicting the main events. The author elicited key ideas and vocabulary from the students by means of brainstorming and discussion. In addition, students were given a list of new words and told to add their own, unknown or troublesome words to this list. Next, individual students read the story out loud in German; parts of the story were translated-not in word-for-word translation but for meaning.

After this phase was completed, students were asked questions orally in German; they were usually able to answer these quite well. For 
homework, students were expected to answer 10-20 written questions. Answers to the written homework were corrected by the students and teacher together.

The following day, students retold the story without referring to the text. Sometimes, this was done with key words written on the board; sometimes, students and instructor built up an outline of the story. After working through the story in this manner, students were given an exam, consisting of 10-15 written questions - the last two questions asked in English-eliciting the significance or meaning of the story.

Students read eight stories during the course of the semester; they reviewed-and were tested-on six grammatical topics. The class was conducted in German, except for the grammatical explanations and interpretations; these were done in English.

\section{The Experimental Group/Experimental Treatment}

The experimental treatment was identical to the conventional treatment except for the following: Students in the experimental group used the computer to check and test their comprehension of the eight stories and six grammatical topics. Instead of doing their question and grammar exercises on paper at home or in class, the experimental group did them in the computer lab once or twice a week during class time; addi- tionally, the experimental group had access to computerized grammar exercises outside of the regular class time.

Computerized quizzes provided the experimental group with immediate feedback; the computer screen displayed a running percentage of correct responses as students worked through the quizzes. When student responses were incorrect, the computer program offered help. Quiz and test questions consisted of vocabulary matching, true/false questions, multiple-choice questions, straight-answer questions, and clozetype questions.

\section{Control Group Results}

The control group, working with the same text materials as the experimental group, were not quizzed or tested using computers. Their pre-test raw scores were as follows: Reading-27.6; Grammar-21.2; and Listening-16.4. Their posttest scores were: Reading-30.6; Grammar-26.5; and, Listening-17.1.

\section{Experimental Group Results}

The experimental group used computers for improving their reading comprehension and drilling grammar. The experimental group had the following pre-test raw scores: Reading-27.8; Grammar-20.4; and, Listening-15.8. Their posttest scores were as follows: Reading-33.3; Grammar-26.7; and, Listening-17.2.

Computer-Assisted Testing

Table 1

Summary of Results

\begin{tabular}{lcccccc}
\hline \multicolumn{2}{c}{ Pre-test } & \multicolumn{4}{c}{ Post-test } \\
\hline Group: & Reading & Grammar & Listen & Reading & Grammar & Listen \\
Possible & 40.0 & 40.0 & 20.0 & 40.0 & 40.0 & 20.0 \\
Control & 27.6 & 21.2 & 16.4 & 30.6 & 26.5 & 17.1 \\
\% Increase & & & & 9.8 & 19.2 & 4.1 \\
Experimental & 27.8 & 20.4 & 15.8 & 33.3 & 26.7 & 17.2 \\
\% Increase & & & & 16.5 & 23.6 & 9.2 \\
& & & & & & \\
\hline
\end{tabular}




\section{Discussion of Results}

As described in this paper, computer-assisted instruction can help students increase their reading comprehension proficiency in intermediate college German courses. Although the increase in performance is by no means dramatic, it is significant.

The rather large increase in the grammar score is probably due to the additional practice time students spent on the computerized grammar drills. Because initial grammar scores were much lower than the scores for reading and listening, it was easier to show a high percentage increase. Similarly, since pre-test reading and listening scores were already high, it was unlikely that these scores would increase by the same percentage as the grammar scores. A future improvement in the experimental design could be the incorporation of a standardized test with three sub-tests of nearly equal difficulty.

\section{Student Response to the Experimental Treatment}

In order to obtain suggestions for improvement, students completed a questionnaire halfway through the course. Some of the suggestions were as follows: 1) allow students to exit the program at any time; 2) allow for an approximate answer, i.e., disregard punctuation and minor spelling errors; 3 ) allow students to go back and change the answer before they are given the answer; 4) provide a built-in dictionary; 5) add more exercises; 6) devote at least one class period per week to work on the computer. Future experimental designs will incorporate such student suggestions.

In addition to suggestions for improvements, students voiced their comments and reactions to the computerized materials. Wrote one student: "The computer really helped me out; I don't think I could have learned the subjunctive without it." Another student wrote: "It is good to work on the stories with the computer (outside of class) because I can manage my time better." Still a third student wrote: "It is easy to understand for those of us who do not have much computer experience."
Although many comments were, as demonstrated by the above-mentioned ones-positive, there were negative ones as well. Said one student: "We did not have a lot of time on the computer." Another student was troubled by the amount of time: "The modules were very timeconsuming for me because I don't type." Still another had problems with the computer: "I erased some of the modules accidentally before I could print them out." Some students found the files themselves troublesome: "There were some minor errors in the files."

\section{Summary}

Using computer-assisted instruction at the intermediate level in German to teach/test reading comprehension and grammar is useful to students. Students do seem to manage their time better. The computerized exercises and quizzes during class time break up the routine. Best of all, perhaps, the frequent quizzes keep students working and learning, in part, because students receive immediate feedback, and the instructor can score and grade computerized quizzes and tests more quickly.

Teachers of intermediate language courses will find it relatively easy to learn how to use an authoring language to create their own quizzes and tutorials. An authoring language with which teachers feel comfortable is a window of pedagogical opportunity and a doorway to better learning with technology.

\section{References}

Barnett, M.A. (1986). Syntactic and lexical/semantic skill in foreign language reading: Importance and interaction. The Modern Language Journal, 70, 343-349.

Beatie, B.A. (1979). A minimal-grammar approach to reading technical German. The Modern Language Journal, 63, 448-451.

Lange, D.L., Raschio, R., \& Wieser, P. (1985). An information processing model for computer-assisted instruction for foreign language reading. Calico Journal, 3(2), 31-37.

Weible, D.M. (1980). Teaching reading skills through linguistic redundancy. Foreign Language Annals, 17, 285-296.

\section{Contributor Profile}

Herman U. Teichert is Associate Professor of German at Western Michigan University. Interested readers may write to him at the following address: Department of Languages and Linguistics, Western Michigan University, Kalamazoo, Michigan 49008. 